\title{
PERFIL DOS ACIDENTES NAS RODOVIAS FEDERAIS EM DEZ DOS QUINZE MUNICÍPIOS QUE COMPÕEM A REGIÃO METROPOLITANA DO RECIFE NO ANO DE 2017
}

\author{
Robert Gomes da Paixão ${ }^{1}$ \\ Alyne Garcia Costa da Paixão
}

\section{RESUMO}

O acidente de transporte terrestre (ATT) é um problema de saúde pública mundial, priorizando jovens em idade produtiva entre 20-40 anos, gerando diversos tipos de sequelas temporárias e permanentes e bilhões em gastos públicos. Descrever o perfil dos acidentes nas rodovias federais na Região Metropolitana do Recife (RMR), irá gerar informações para combate a esse agravo. Trata-se de um estudo de caráter retrospectivo, descritivo, transversal e ecológico, realizado por meio de dados, disponibilizados pela Polícia Rodoviária Federal (PRF), sendo inclusos todos os casos nas rodovias federais, analisados sem distinção de idade, sexo e raça. Buscando identificar as variáveis dia da semana, turno, tipo, causa, classificação das vítimas e óbitos. Ocorreram, em 2017, 1.383 ATT na RMR. Recife foi mais prevalente $(34,92 \%)$, a SEGUNDA-FEIRA teve $16,99 \%$, a colisão representou $61,82 \%$, a falta de atenção $49,45 \%$, os acidentes com vítimas graves foram $63,41 \%$, óbito $4,8 \%$ e o turno do dia $65,58 \%$. $40 \%$ da RMR apresentou um perfil de colisões por falta de atenção na SEGUNDA-FEIRA durante o dia. Os três primeiros municípios desta lista, integraram o ranking dos maiores PIB em 2017. Recife apresentou índice compatível com estados referencias em ATT, mostrando a necessidade de avaliar as condições do trânsito na RMR.

Palavras-chave: Acidente de trânsito; Causas externas; Morbidade; Mortalidade; Epidemiologia.

\footnotetext{
${ }^{1}$ Bacharel em enfermagem - Universidade Maurício de Nassau - Recife-PE.

${ }^{2}$ Bacharel em enfermagem - Universidade Maurício de Nassau - Recife-PE.
} 


\title{
PROFILE OF ACCIDENTS ON FEDERAL ROADS IN TEN OF THE FIFTEEN MUNICIPALS THAT MAKE A METROPOLITAN RECIFE REGION YEAR 2017
}

\begin{abstract}
The land transport accident (ATT) is a worldwide public health problem, prioritizing young people of working age between 20-40 years, generating several types of temporary and permanent sequelae and billions in public spending. Describing the profile of accidents on federal highways in the Metropolitan Region of Recife (RMR), will generate information to combat this problem. This is a retrospective, descriptive, cross-sectional and ecological study, carried out through data, made available by the Federal Highway Police (PRF), including all cases on federal highways, analyzed without distinction of age, sex and race. Seeking to identify the variables day of the week, shift, type, cause, classification of victims and deaths. In 2017, 1,383 ATT occurred in the RMR. Recife was more prevalent (34.92\%), MONDAY had $16.99 \%$, the collision represented $61.82 \%$, the lack of attention $49.45 \%$, accidents with serious victims were $63.41 \%$, death $4.8 \%$ and the day shift $65.58 \% .40 \%$ of RMR showed a collision profile due to lack of attention on MONDAY during the day. The first three municipalities in this list were included in the ranking of the highest GDPs in 2017. Recife presented an index compatible with reference states in ATT, showing the need to assess traffic conditions in the RMR
\end{abstract}

Keywords: Traffic accident; External causes; Morbidity; Mortality; Epidemiology. 


\section{INTRODUÇÃO}

A Organização Mundial da Saúde (OMS), afirma que o Acidente de Transporte Terrestre (ATT) causou, em 2010, 1,2 milhão de mortes e média de 35 milhões de feridos no mundo (LEOPOLDO et al., 2015). Segundo a OMS, por ano, 50 milhões de pessoas sofrem algum tipo de ATT e, desse total, cerca de 1,3 milhão evoluem para óbito (MEDEIROS et al., 2017). A OMS estima que até 2030, esse número chegará a 2,4 milhões. Nas Américas, já alcançamos os 140 mil óbitos e cinco milhões de lesionados por ATT (ANDRADE, 2015). Atualmente, o Brasil tem média anual acima de 150 mil feridos e mortos, sendo o quinto no ranking com maior índice de ATT no mundo (MEDEIROS et al., 2017) e fica atrás apenas da Índia, China, EUA e Rússia (SANTOS et al., 2018).

Por esse motivo, o cenário epidemiológico do Brasil está mudando gradativamente com números preocupantes desde a década de 1980, onde as doenças infecto-parasitárias começaram a dar lugar as degenerativas, crônicas e causas externas. Esta última, compreende os atos de violência e os acidentes, que estão ganhando cada vez mais notoriedade mundial há quase 40 anos, chegando a ser responsável por quase $9 \%$ da mortalidade global, o que representa aproximadamente cinco milhões de pessoas (ANDRADE, 2015). Das causas externas, os ATT acometem todas as faixas etárias em se tratando de morbimortalidade, em especial, os adultos jovens (MEDEIROS et al., 2017).

Devido a essas mudanças no Brasil, a mortalidade por causas externas ocupa a terceira posição segundo inquérito nacional, apontando que a maioria dos internamentos hospitalares ocorre por ATT (ANDRADE, 2015). Por dia, morrem milhares pessoas por lesões traumáticas, perdendo de 30 a 40 anos de vida ativa, principalmente dos jovens entre 20 e 40 anos de idade, que mantém parte da economia ativa. Para cada vítima que morre, outras 
sobrevivem, todavia, com sequelas (SANTOS et al., 2018). Essas são lesões ou afecções permanentes ou crônicas decorrentes de doenças ou traumas, podendo levar a incapacidades físicas (ANDRADE, 2017), emocionais, econômicas, invalidez ou óbito (MEDEIROS et al., 2017).

Essa problemática faz com que os gastos públicos variem entre 1 e $2 \%$ do Produto Interno Bruto (PIB) dos países com maior índice de ATT, chegando a US\$ 500 bilhões/ano. Segundo o Ministério da Saúde (MS), no Brasil esse custo já ultrapassou a casa dos 28 bilhões/ano. No Nordeste, onde há um grande excedente no número de veículos e certo déficit na fiscalização de trânsito, devido a extensão territorial e a falta de recursos humanos, os valores gastos com os ATT, são elevados, chegando a superar a receita, como é o caso do município de Natal, no Rio Grande do Norte (RN), que possui uma receita de $R \$ 2$ bilhões e teve um gasto de $R \$ 2,65$ bilhões. Esse valor corresponde a 5,08\% do PIB do estado do RN (MEDEIROS et al., 2017).

Com base nessa gravidade, o MS tomou algumas medidas, mesmo que de modo significativo não consigam solucionar completamente o problema, sendo elas as seguintes: mais rigor nas leis de trânsito, descentralização do controle das vias para os municípios, melhoria na segurança dos veículos e investimentos na fiscalização eletrônica. No ano de 2001, o MS notou que o impacto dos ATT alterou a vida social e criou a Política Nacional de Redução da Morbimortalidade por acidentes e violência. Bem como, em 2006, o Projeto de Vigilância e Acidentes (VIVA) (MEDEIROS et al., 2017).

Foi criado pelo MS o Projeto Vida no Trânsito (PVT), um fragmento da meta Road Safety in 10 countries (RS 10), formulada pela Organização das Nações unidas (ONU), como um dos principais elementos para alcançar as metas da Década de Ações para Segurança no Trânsito, com foco em direção perigosa e na embriaguez ao volante (2011 a 2020). Mesmo presente em todas as capitais, com projetos e implementações para reduzir os ATT, os números mostram-se bem representativos. No Brasil, em 2015, 664,2 mil pessoas 
sofreram algum tipo de ATT, resultando em 43 mil óbitos e 525 mil sequelas permanentes (MEDEIROS et al., 2017).

Diante do exposto, o presente trabalho visa apresentar conteúdo sobre a epidemiologia dessa gravidade, contribuindo para o desenvolvimento de políticas públicas e estratégias para atenuar $\mathrm{o}$ alto índice de morbimortalidade que acomete vários países do mundo. Diante da extensão do problema, é importante conhecer quais os tipos de acidentes, suas principais causas e circunstâncias, para que as autoridades responsáveis tomem conhecimento das informações e articulem medidas cabíveis de combate e prevenção desse agravo.

$O$ trabalho em questão tem como objetivo identificar o perfil dos acidentes nas rodovias federais em dez dos quinze municípios de compõem a Região Metropolitana do Recife (RMR), no ano de 2017. Só integraram a pesquisa aqueles que apareceram nas notificações da Polícia Rodoviária Federal (PRF), por esse motivo, apenas dez municípios foram destacados.

\section{METODOLOGIA}

Foi realizado um estudo de caráter retrospectivo, descritivo, transversal e ecológico, com abordagem quantitativa, em que a unidade de análise foram os acidentes de trânsito ocorridos em Rodovias Federais na RMR, no ano de 2017. Para obter os resultados, coletamos dados secundários da PRF, utilizando os seguintes critérios para inclusão na pesquisa e variáveis de estudo: Ano: 2017, local: RMR, evento ter ocorrido em qualquer via federal dentro dos limites da região pré-estabelecida, todos os gêneros e idades, e, como critério de exclusão, as com significativo similar e ou repetidas.

A planilha matriz foi composta por aproximadamente 89.300 acidentes ocorridos em todo país, desse total, separamos os casos referentes ao estado de Pernambuco, em seguida, filtramos as variáveis dos municípios da RMR 
que foram citados pela PRF, no caso, dez, rendendo uma amostra de 1.383. Separamos as bases por município, extraímos as referências de cada incidente em novas planilhas Excel 2017, filtrando, assim, as nossas variáveis: dia da semana, turno, tipo de acidente, causa do acidente, classificação das vítimas quanto a gravidade e óbito.

Os gráficos do Word expostos nesta pesquisa foram construídos por meio de estatística descritiva, após análise, coleta e cálculo dos valores obtidos conforme os critérios de inclusão. Os valores demonstrados entre os percentuais das variáveis foram calculados e sofreram arredondamento pelo valor total de notificações (1.383). No texto dos resultados e das discussões, os percentuais são calculados e apresentados também pelo total da sua variável, para ampliar a compreensão dos resultados obtidos. Cada município será apresentado em gráfico individual e será apresentado um gráfico geral com o somatório dos elementos.

Do ponto de vista da ética em pesquisa, foi considerado o previsto na resolução no 510 de 7 de abril de 2016, sobretudo no aspecto que trata sobre a não obrigatoriedade de registrar nem avaliar pelo sistema CEP/CONEP pesquisa que utilize informações de acesso público, nos termos da Lei no 12.527, de 18 de novembro de 2011, pesquisa que utilize informações de domínio público, e pesquisa com bancos de dados, cujas informações são agregadas, sem possibilidade de identificação individual.

\section{RESULTADO E DISCUSSÃO}

\subsection{Perfil dos acidentes rodoviários na RMR por dia da semana}

Sendo feita a distribuição dos dados de acordo com cada dia da semana, mostrou-se uma diferença pequena $(5,14 \%)$ entre o primeiro (SEGUNDA-FEIRA 16,99\%) e o último colocado (TERÇA-FEIRA11,85\%). Dessa forma, observamos que na maioria dos municípios da RMR, que 
Revista Científica do Corpo de Bombeiros Militar de Pernambuco

Artigo Publicado no Vol.06 N.16 - Edição Especial 2020 - ISSN 2359-4829

Versão on-line disponível em: http://www.revistaflammae.com

integraram a pesquisa, a SEGUNDA-FEIRA foi o dia em que ocorreu o maior número de acidentes (235), seguida pela QUINTA-FEIRA que apresentou 215 $(15,54 \%)$ casos no mesmo período.

Figura 1 - Perfil dos acidentes quanto ao dia da semana segundo a (PRF).

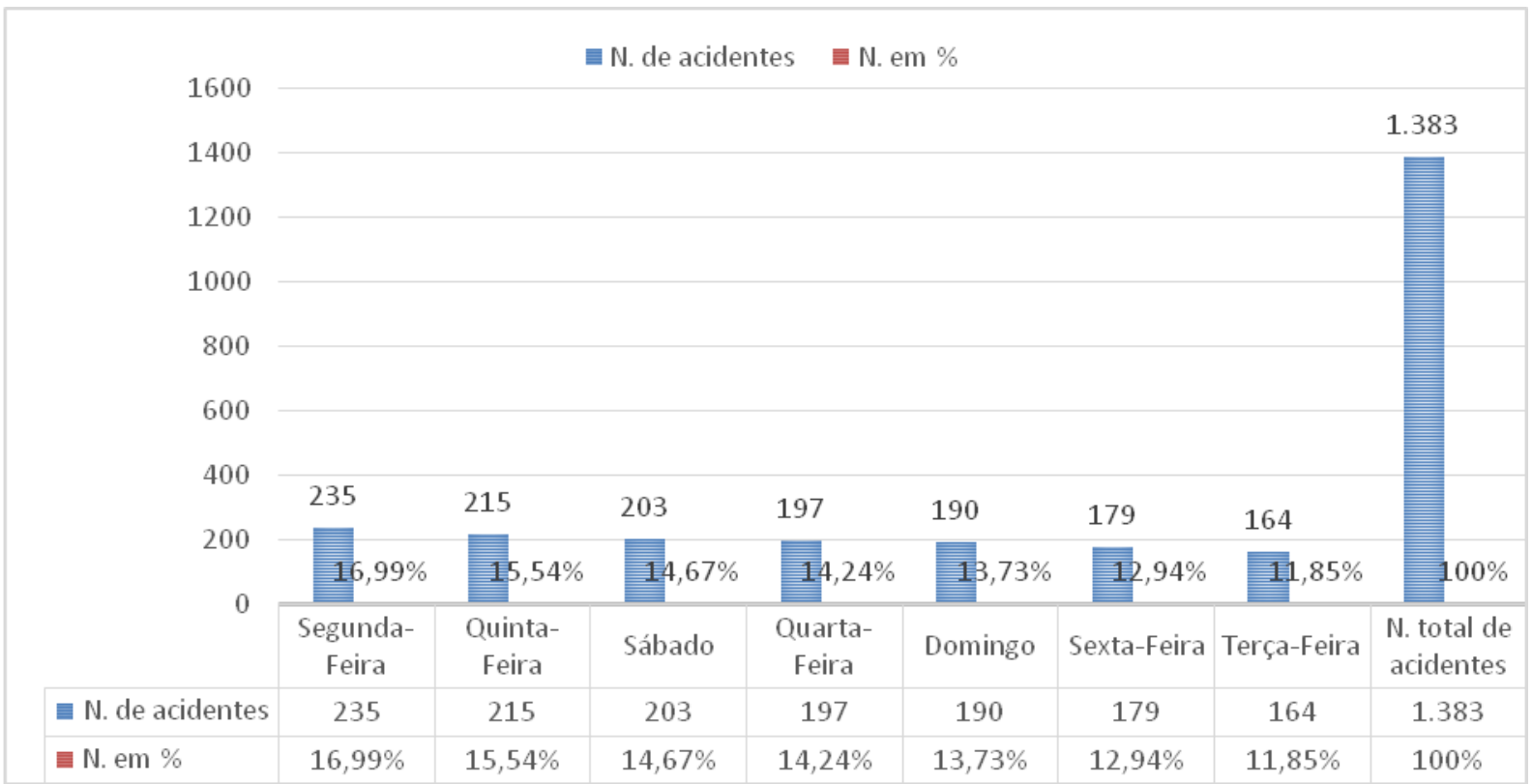

Fonte- Polícia Rodoviária Federal (PRF).

Os resultados para cada dia da semana foram homogêneos, com pouca variação no percentual entre o primeiro e o último colocado, indicando que os altos índices semanais se mantêm. A SEGUNDA-FEIRA e a QUINTA-FEIRA apresentaram 16,99\% e 15,54\% respectivamente, enquanto a SEXTA-FEIRA e a TERÇA-FEIRA apresentaram 12,94\% e 11,85\%. O fim de semana (SEXTAFEIRA e SÁBADO) obteve $27,61 \%$, indicando que $72,39 \%$ dos acidentes ocorreram no início e metade da semana. Ao confrontarmos esta pesquisa com o estudo de Dias et al. (2017) em Sobral (Ceará), identificamos resultados divergentes, onde houve maior prevalência durante o fim de semana, totalizando $69,5 \%$ dos casos, sendo o DOMINGO notório ao atingir 33\% dos casos.

Quando observarmos os dados de Marcelo (2017), em seu estudo sobre a mortalidade por acidentes de trânsito em Aracajú, identificamos que a 
SEXTA-FEIRA foi o dia da semana com maior prevalência de acidentes, enquanto isso, a TERÇA-FEIRA ficou logo em seguida com $30,8 \%$ dos casos. Dessa forma, é possível observar que os dias da semana mais prevalentes nessa pesquisa, foram os menos prevalentes neste estudo.

Segundo Barros et al. (2018), em sua pesquisa sobre a VIII região de saúde de Pernambuco (sertão), o SÁBADO foi o dia da semana com maior prevalência $17,9 \%$, enquanto a QUINTA-FEIRA obteve o menor resultado $13,1 \%$.Ao analisar os dados do autor, foi observado que assim como neste estudo, houve pouca variação entre primeiro e último colocado, apenas 4,8\% e, comparando com esta pesquisa, podemos observar a similaridade entre as mesmas, pois existe diferença em relação ao posicionamento das variáveis, mas na distribuição dos dados, ambas apresentações indicam que durante a semana os ATT mantiveram-se quase iguais durante todos dias. Dessa forma, tanto a VIII região de saúde quanto na I (RMR), as rodovias apresentam altos índices de ATT diariamente.

Considerando a comparação dos elementos encontrados nesta pesquisa com os resultados dos autores citados, tanto do mesmo estado, bem como de outros, é possível observar que há uma grande variação em relação aos achados quanto ao dia da semana, indicando que parte da RMR apresenta uma característica diferente das outras em se tratando de ATT.

\subsection{Perfil dos acidentes rodoviários na RMR por tipo de evento}

A colisão foi a primeira colocada com 855 acidentes que representaram $61,82 \%$ dos ocorridos, demonstrando uma diferença de 58,86\% em relação ao último colocado, tombamento, que apresentou 41 incidentes, alcançando uma margem 2,96\% dos casos. O segundo tipo mais evidente foi causado pela saída do leito carroçável (quando o veículo de desloca da faixa de rolamento em qualquer direção) contabilizando 147 eventos, representando 10,62\% do total de acidentes. 
Revista Científica do Corpo de Bombeiros Militar de Pernambuco

Artigo Publicado no Vol.06 N.16 - Edição Especial 2020 - ISSN 2359-4829

Versão on-line disponível em: http://www.revistaflammae.com

Figura 2 - Perfil dos acidentes segundo a classificação da (PRF) para cada evento.

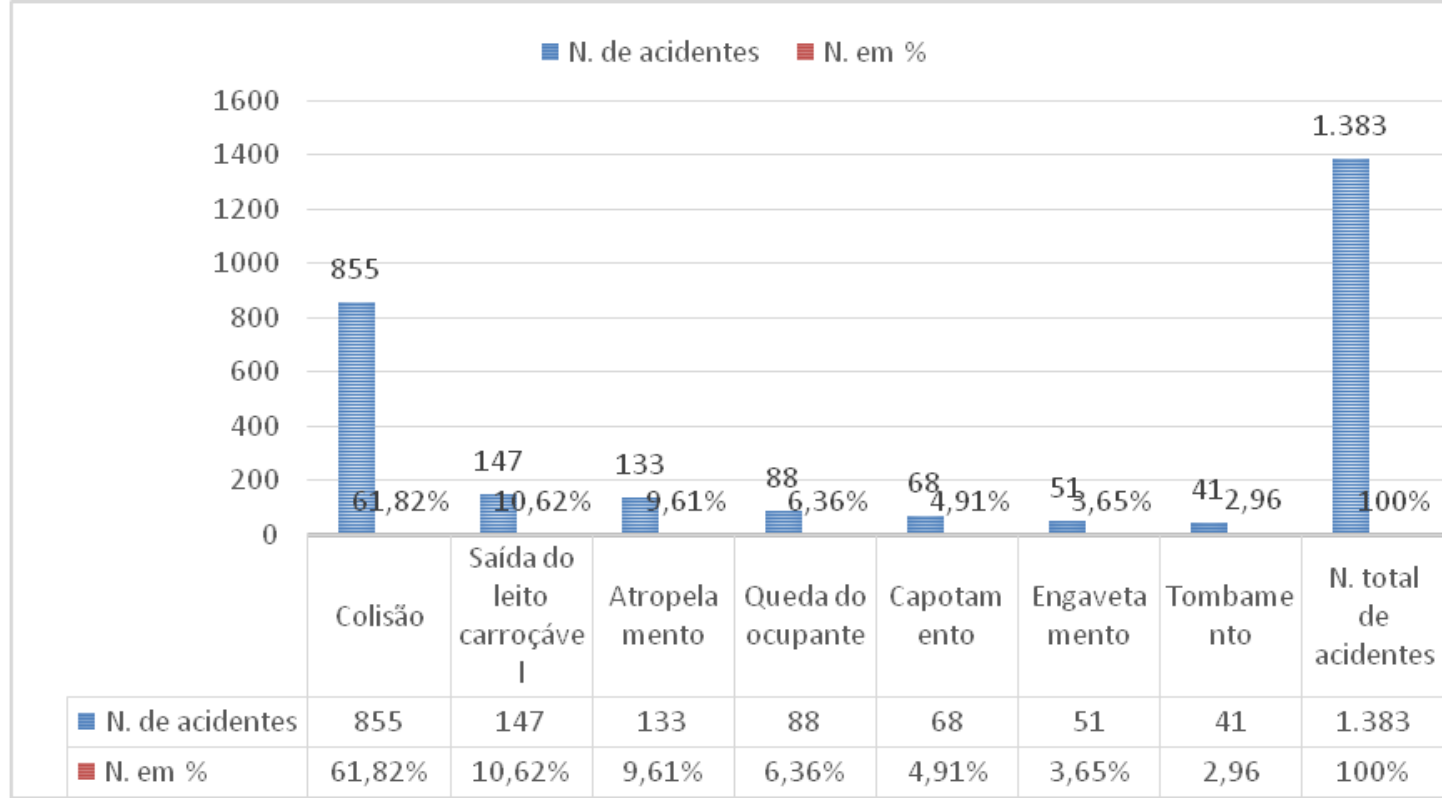

Fonte- Polícia Rodoviária Federal (PRF).

De acordo o Ipea (2015), representando dados de todo Brasil, as colisões representaram maior índice com $33,7 \%$ dos casos.Já Dias et al. (2017), em seu estudo, o tipo de acidente mais prevalente foi a colisão, com $50 \%$. Soares et al. (2018), demonstrando dados similares, afirma que a colisão representou 58\% dos tipos de acidentes. Segundo Marcelo (2017), em seu estudo sobre a mortalidade por acidentes de trânsito em Aracajú, a colisão foi o tipo de acidente que provocou mais mortes (59\%), seguida pelo atropelamento, sendo responsável por 25\%. Dessa forma, Ipea (2015), Dias et al. (2017), Soares et al. (2018) e Marcelo (2017) também evidenciam que as colisões foram prevalentes entre os ATT nas Rodovias Federais.

Segundo Barros et al. (2018), a colisão foi responsável por $80,7 \%$ dos ATT, seguida pela saída do leito carroçável com 10,0\%, devido à falta de sinalização, desrespeito dos condutores, precariedade do asfalto, união entre rodovias e vias coletoras que possuem diferença entre os limites de velocidade. Segundo a justificativa, o fator social contribui para a prevalência dos acidentes, uma vez que é grande o número de pessoas desabrigadas que 
acabam buscando as margens das rodovias, alimentando o fluxo de pedestres e acidentes típicos, por exemplo atropelamento de pedestres e dos animais na via.

De acordo com os resultados apresentados nesse estudo em comparação com as demais pesquisas citadas, identificamos que a RMR apresenta uma convergência considerável em relação aos tipos de acidentes nas rodovias federais nas demais localidades citadas, uma vez que essa região apresentou resultados de colisão como causa predominante.

\subsection{Perfil dos acidentes rodoviários na RMR quanto às causas}

Fazendo análise, quantificação e a distribuição dos resultados é possível observar que a variável falta de atenção do condutor (termo utilizado pela PRF) foi a recordista de acidentes na RMR, sendo responsável por 684 ocorridos, atingindo um percentual de 49,45\%, gerando uma grande diferença $(48,52 \%)$ em relação à última variável, mal súbito, com 13 ocorridos, alcançando uma margem de $0,93 \%$ dos casos. A segunda maior causa foi não guardar a distância devida, que provocou 160 acidentes e obteve $11,56 \%$ do total.

Figura 3 -Perfil dos acidentes quanto às causas dos eventos segundo a (PRF).

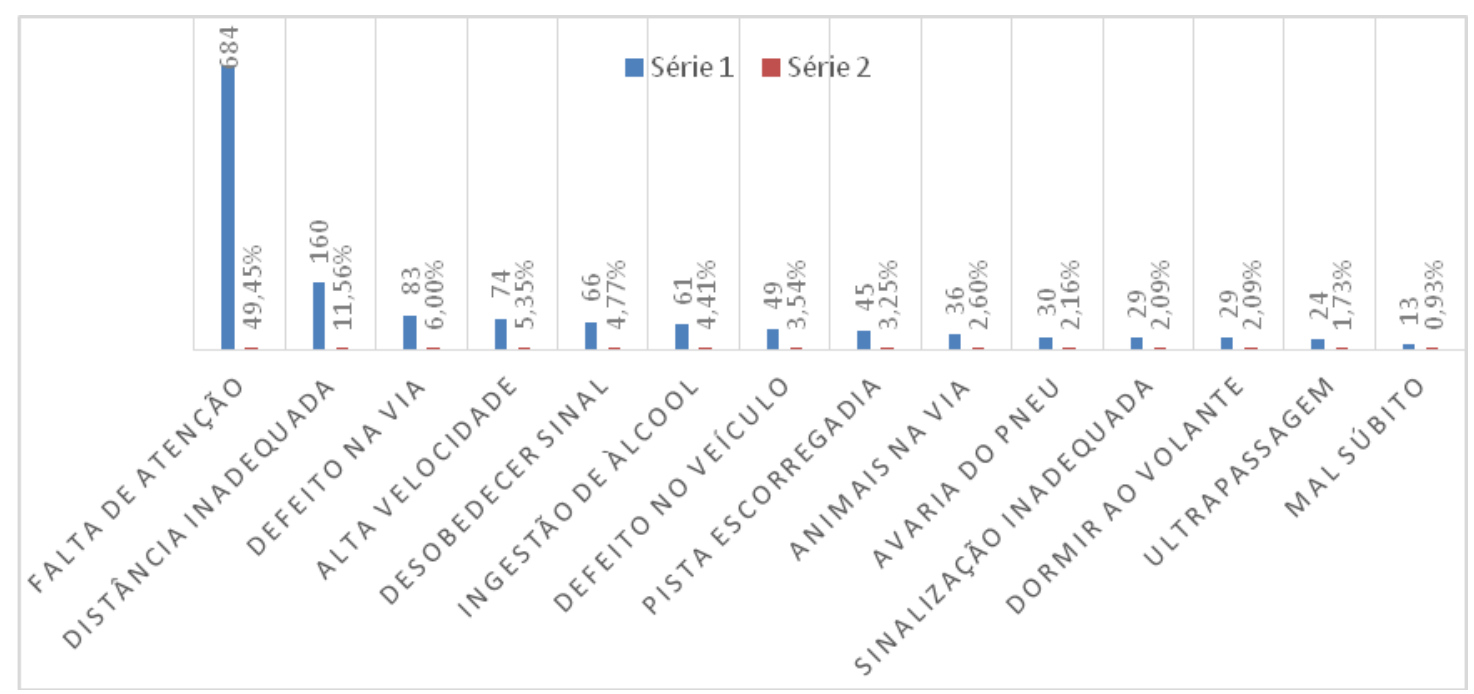

Fonte- Polícia Rodoviária Federal (PRF) 
Com a facilidade na liberação de crédito, consórcios e financiamentos, a população passou a optar por transportes particulares, deixando as vias cada vez mais densas, aumentando o fluxo nas rodovias, o que pode refletir diretamente no número de eventos no Nordeste, que aumentou $81,5 \%$ Bertho et al. (2016).

Segundo o Ipea (2015), ao realizar uma análise nas bases de dados da PRF, avaliando as principais causas dos acidentes, verificou-se que a falta de atenção dos condutores destacou-se com $32,6 \%$ das injurias envolvendo óbitos. Velocidade incompatível com a via teve $13,1 \%$, ultrapassagem indevida $7,8 \%$ e ingestão de álcool 6,5\%. O órgão ressalta a importância da educação no trânsito, realizando a conscientização dos condutores em relação ao uso de celular, equipamentos de áudio e vídeo, possíveis indutores da falta de atenção.

De acordo com Soares et al (2018), a falta de atenção teve o maior índice em relação aos demais tipos de acidentes, chegando a 33\% do total. Segundo Barros et. al. (2018), no ano de 2014, nas rodovias federais, tiveram quase 8.300 de casos fatais, onde $23 \%$ dos óbitos foram causados por infrações de alta velocidade e ultrapassagem perigosa.

De acordo com os resultados apresentados por esses autores em relação a causa dos ATT, é possível observar que a RMR apresentou resultados superiores aos dessas pesquisas, abrindo portas para hipóteses sobre a atenção dos condutores na metrópole pernambucana, ema vez que a variável falta de atenção foi predominante nesta localidade. Diante do exposto podemos refletir sobre as possíveis circunstâncias que levaram a tais atos. Seria a fadiga pela jornada de trabalho? A tecnologia com seus itens de áudio e vídeo? O álcool? O que sabemos, é que segundo os resultados dos dados coletados através da PRF, recife apresenta resultados desfavoráveis e preocupantes para a sociedade e para a economia municipal. 


\subsection{Perfil dos acidentes rodoviários na RMR quanto a presença de vítimas}

Dos 1.383 eventos nas rodovias, constatamos que 877 acidentes $(63,41 \%)$ foram com vítimas graves com os mais variados tipos de lesões e até óbitos, enquanto nos 506 acidentes $(36,58 \%)$ as vítimas apresentaram ferimentos leves ou saíram ilesas. A diferença entre os percentuais das variáveis apresentadas foi de $26,83 \%$ a mais em relação as gravidades,o que nos leva a refletir sobre este cenário, uma vez que tais incidentes necessitam de acionar muitos recursos para a sua solução, quando possível.

Figura 4 - Perfil dos acidentes quanto a classificação de vítimas segundo a (PRF).

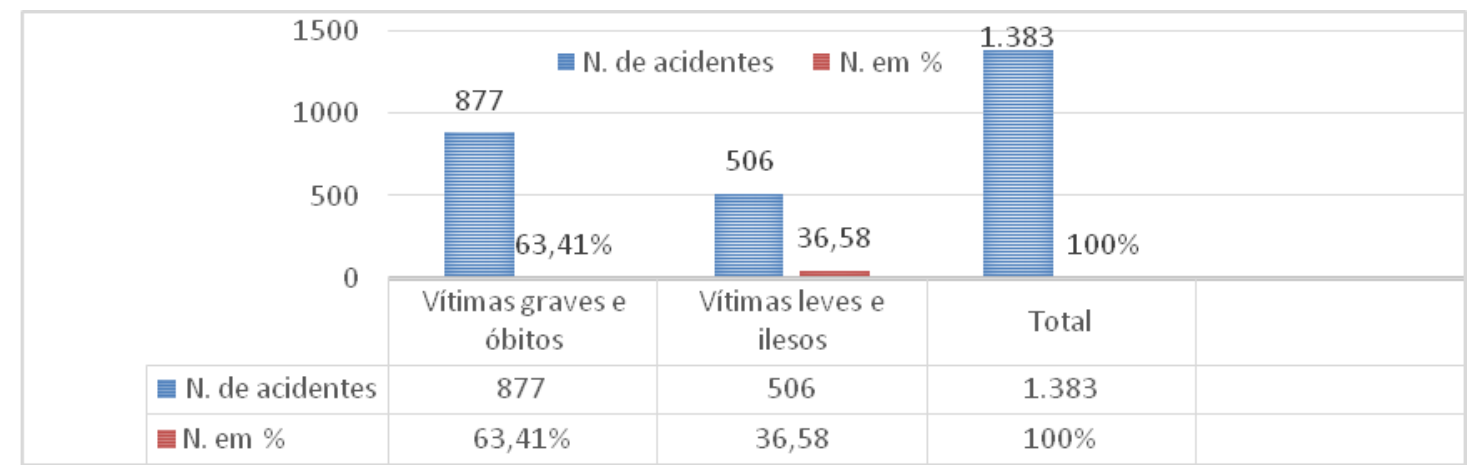

Fonte- Polícia Rodoviária Federal (PRF)

De acordo com dados do Departamento de Informática do Sistema Único de Saúde (Datasus), do MS, os ATT no Brasil são responsáveis por aproximadamente 43 mil óbitos por ano, só em 2014 foram 169.163 acidentes, o que representa uma das principais causas de morte no país. Desse total de perdas, $20 \%$ (8.227) ocorrem nas rodovias federais fiscalizadas pela PRF (IPEA, 2015).

Segundo Bertho et al. (2016), o número de óbitos por ATT seguiu tendenciosamente o aumento da frota de veículos, passando de 29 mil para quase 43 mil mortes em todo país, um crescimento aproximado de $48 \%$. O número de óbitos no nordeste do país passou de 6.529 para 11.853, gerando um aumento próximo de $82 \%$. Dentre os estados do nordeste, o Piauí registrou 
a maior taxa de óbitos em sua capital, destacando 151,34 óbitos masculinos e 25,83 óbitos femininos por 100 mil habitantes. Enquanto isso, Recife, a capital pernambucana apresentou um total de 94,67 óbitos por 100 mil habitantes no mesmo período, considerando ambos os sexos.

Mesmo depois das criações de medidas de combate as morbidades e mortalidades decorrentes dos ATT, os índices continuam muito elevados, onde os estados de Sergipe e Piauí lideram no ranking dos ATT (MEDEIROS et al., 2017). De acordo com Barros et al. (2018), o aumento populacional associado ao crescimento econômico, tem influência direta sobre os altos índices de acidentes. Segundo o autor, com base nos dados crescentes, em até dez anos, o número de vítimas fatais poderá ultrapassar os 2 milhões, citando o Nordeste como uma das regiões mais prevalentes do Brasil, e mais especificamente, os estados da Bahia, Pernambuco e Ceará, como os mais violentos no ano de 2015.

Nos últimos anos a violência no trânsito ganhou destaque mundial, deixando em alerta as autoridades dos países com maior índice de ATT, onde está havendo um contínuo engajamento na tentativa de mudar a situação atual. Levando em consideração ser as causas externas o terceiro causador de mortes no Brasil, foi criado em 2003, o serviço de atendimento Móvel de Urgência (SAMU) para atuar em conjunto com as equipes multiprofissionais na tentativa de mudar esse cenário em relação as vítimas, morbidades, óbitos e gastos públicos, esse último reflete na economia (DIAS et al., 2017).

Realizando a comparação da RMR com as demais localidades citadas nesta pesquisa, identificamos que a taxa de óbito por número de acidentes foi de 4,84\%, mas ainda assim, além das perdas, houve um número alto de pessoas envolvidas (3.963) evoluindo para gravidade, gerando diversas condições desfavoráveis para as famílias e coletividade, condição essa, que não pode passar despercebida pelos órgãos competentes. 


\subsection{Perfil dos acidentes rodoviários na RMR por turno}

A análise da variável turno, mostrou que 907 acidentes ocorreram durante o dia, representando $65,58 \%$ dos casos, enquanto 476 casos ocorreram no período noturno, contabilizando $34,42 \%$ do total dos eventos ocorridos, indicando uma diferença de $31,17 \%$ entre os turnos, sendo o período diurno predominante na ocorrência dos eventos todos os municípios.

Figura 5 - Perfil dos acidentes quanto ao turno segundo a classificação da (PRF).

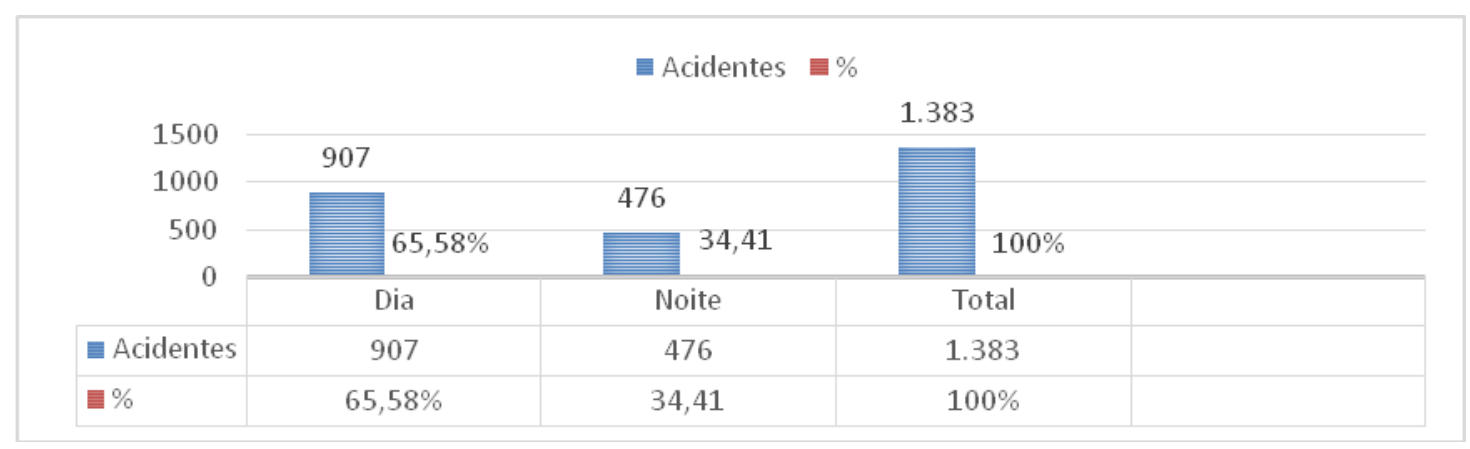

Fonte - Polícia Rodoviária Federal (PRF).

De acordo com Marcelo (2017), em seu estudo sobre a mortalidade por acidentes de trânsito em Aracajú, divergindo dessa pesquisa, o turno da noite foi mais prevalente, contabilizando $35,9 \%$ dos acidentes que envolveram vítimas fatais, em seguida, o turno vespertino, chegando a $26,9 \%$ dos eventos. Os turnos da manhã e da madrugada tiveram os menores resultados.

De acordo com Schmidt (2018), no Rio Grande do Sul (RS), levando em conta as variações do fuso-horário, os acidentes foram predominantes durante o dia, enquanto na Bahia a maioria dos acidentes aconteceram a noite. Dessa forma, observamos uma variação nos resultados do autor, indicando que os resultados de determinada pesquisa podem variar dependo do local do estudo. Isto pode ser observado quando confrontamos os dados de Schmidt com esta 
pesquisa, uma vez que os resultados são similares em um ponto, e divergem em outro.

Segundo Barros et al. (2018), nas rodovias federais que cortam a VIII Região de Saúde, no sertão Pernambucano, a maior ocorrências dos ATT ocorreu entre às 18:00 e 19:00hs, podendo ser consequência da visibilidade diminuída do condutor, fadiga durante o dia causando déficit nos reflexos e na atenção, podendo também haver relação direta com a ingestão de álcool, sendo essa última uma das principais causas de ATT.

Sem uma pesquisa mais detalhada não tem como afirmar com exatidão se a fase do dia tem total relação com o número de acidentes. Para tal, é necessário criar uma teoria, aplicá-la e posteriormente testar os seus resultados. Mas se considerarmos os pontos em que a autoridades vez ou outra fixam suas campanhas de educação no trânsito (dirigir alcoolizado, usar celular enquanto conduz, não respeitar o transito, ultrapassar sinal vermelho, enfim), podemos supor que a falta de atenção é um condutor para a causa de acidentes.

\subsection{Perfil dos acidentes rodoviários na RMR por município}

Recife foi notoriedade, totalizando $34,92 \%$ dos acidentes, seguido por Jaboatão dos Guararapes e Cabo de Santo Agostinho que apresentaram $15,76 \%$ e $12,87 \%$ respectivamente. Os dois últimos colocados foram Itapissuma com 1,95\% dos acidentes e Ipojuca, com 0,28\%. Em $40 \%$ dos municípios, segundo os dados coletados, os acidentes ocorridos apresentam um perfil de colisões por falta de atenção do condutor nas Segundas-Feiras durante o dia. Durante a coleta dos dados, foi observado que dentre as anotações dos agentes da PRF quanto a causa do acidente, estava assinalado o item falta de atenção. 
Figura 6 - Perfil dos acidentes por município (autor).

\section{RECIFE}

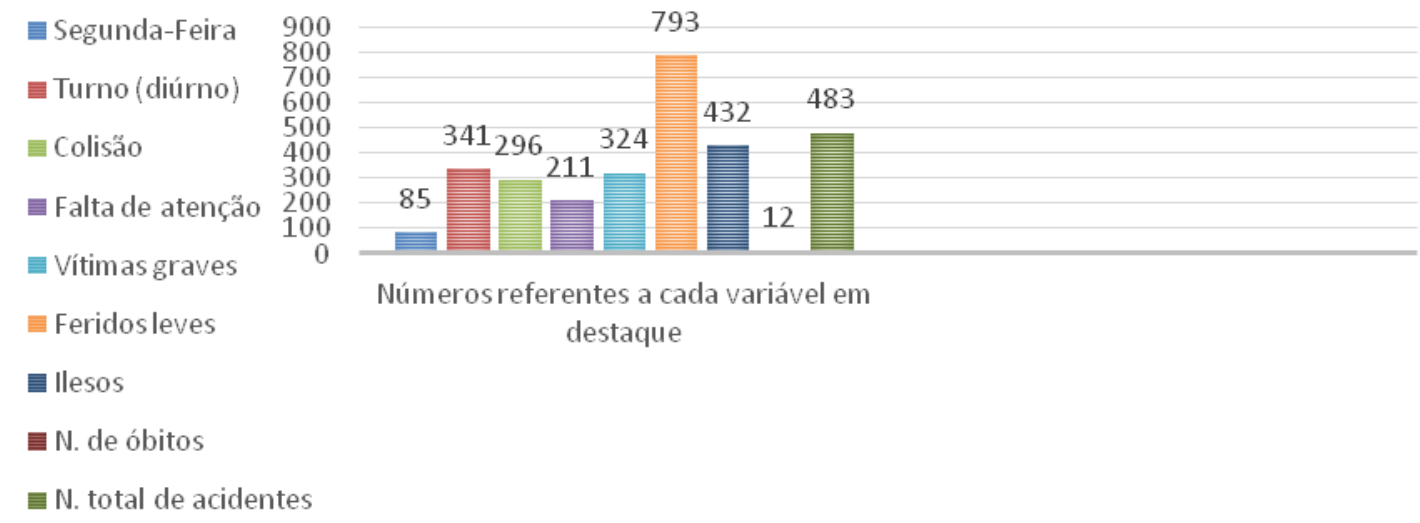

Fonte- Polícia Rodoviária Federal (PRF).

Figura 6.1 - Perfil dos acidentes por município (autor).

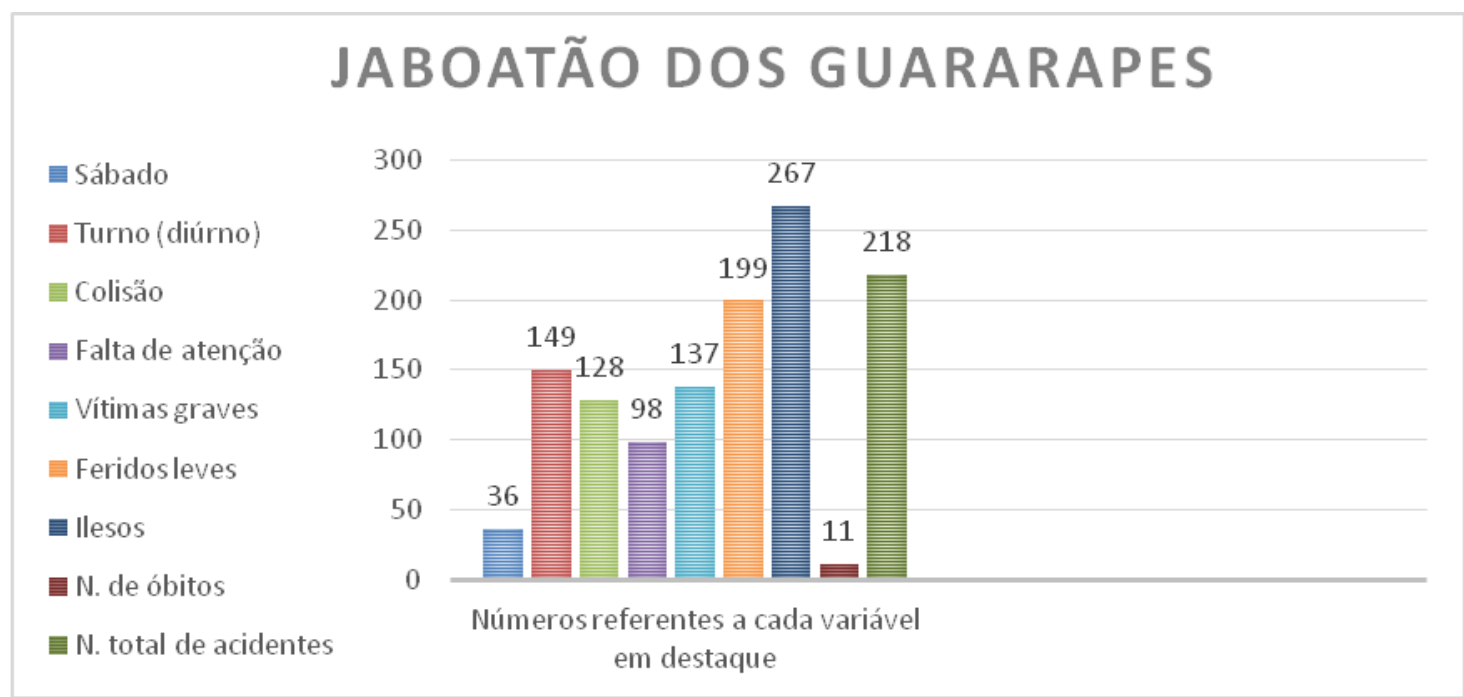

Fonte- Polícia Rodoviária Federal (PRF). 
Figura 6.2 - Perfil dos acidentes por município (autor).

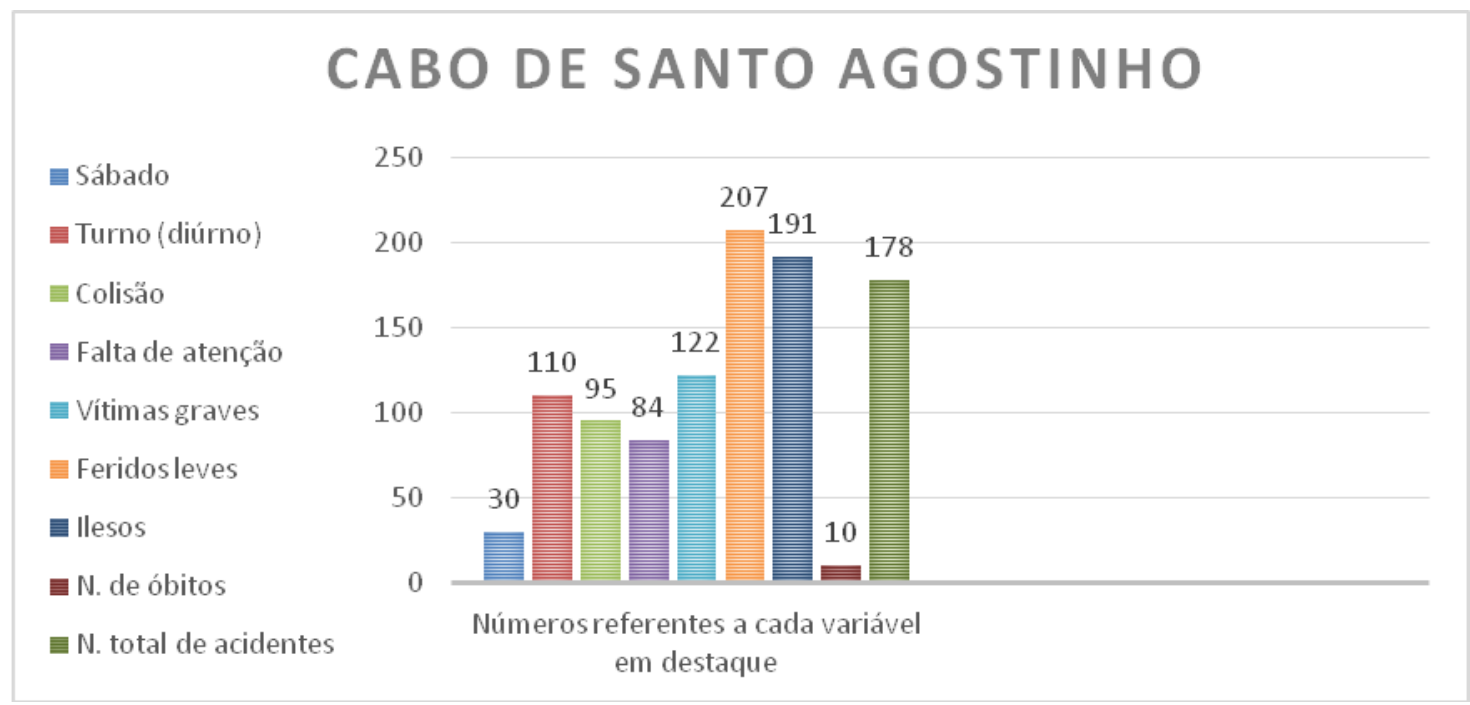

Fonte- Polícia Rodoviária Federal (PRF).

Figura 6.3 - Perfil dos acidentes por município (autor).

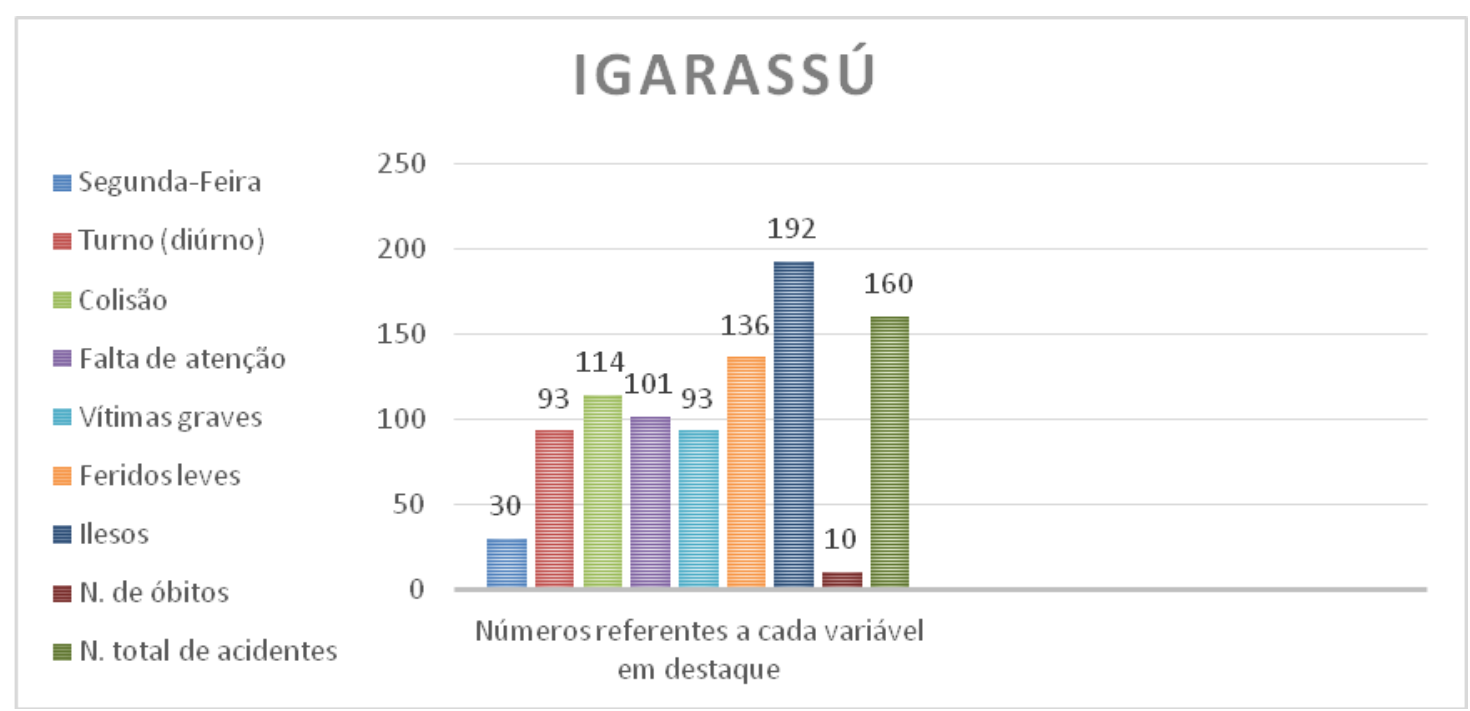

Fonte- Polícia Rodoviária Federal (PRF). 
Revista Científica do Corpo de Bombeiros Militar de Pernambuco

Artigo Publicado no Vol.06 N.16 - Edição Especial 2020 - ISSN 2359-4829

Versão on-line disponível em: http://www.revistaflammae.com

Figura 6.4 - Perfil dos acidentes por município (autor).

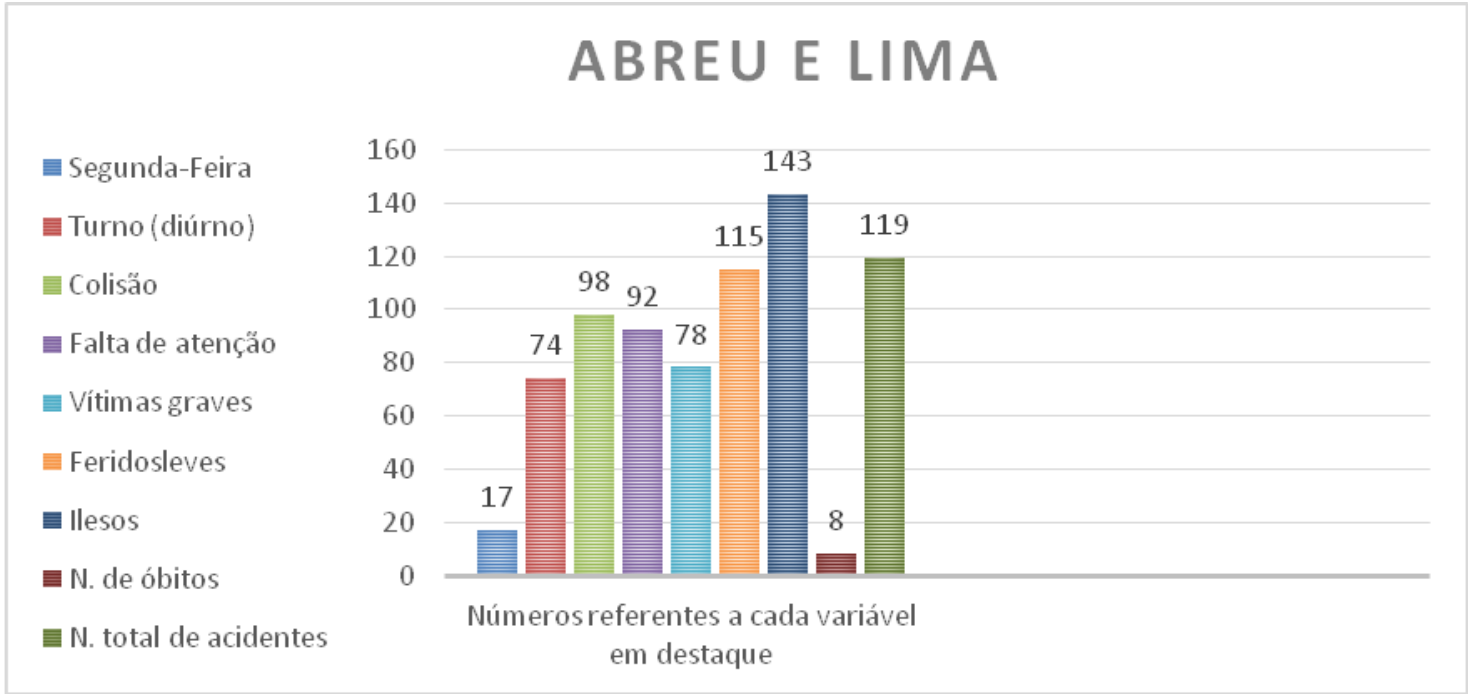

Fonte- Polícia Rodoviária Federal (PRF).

Figura 6.5 - Perfil dos acidentes por município (autor).

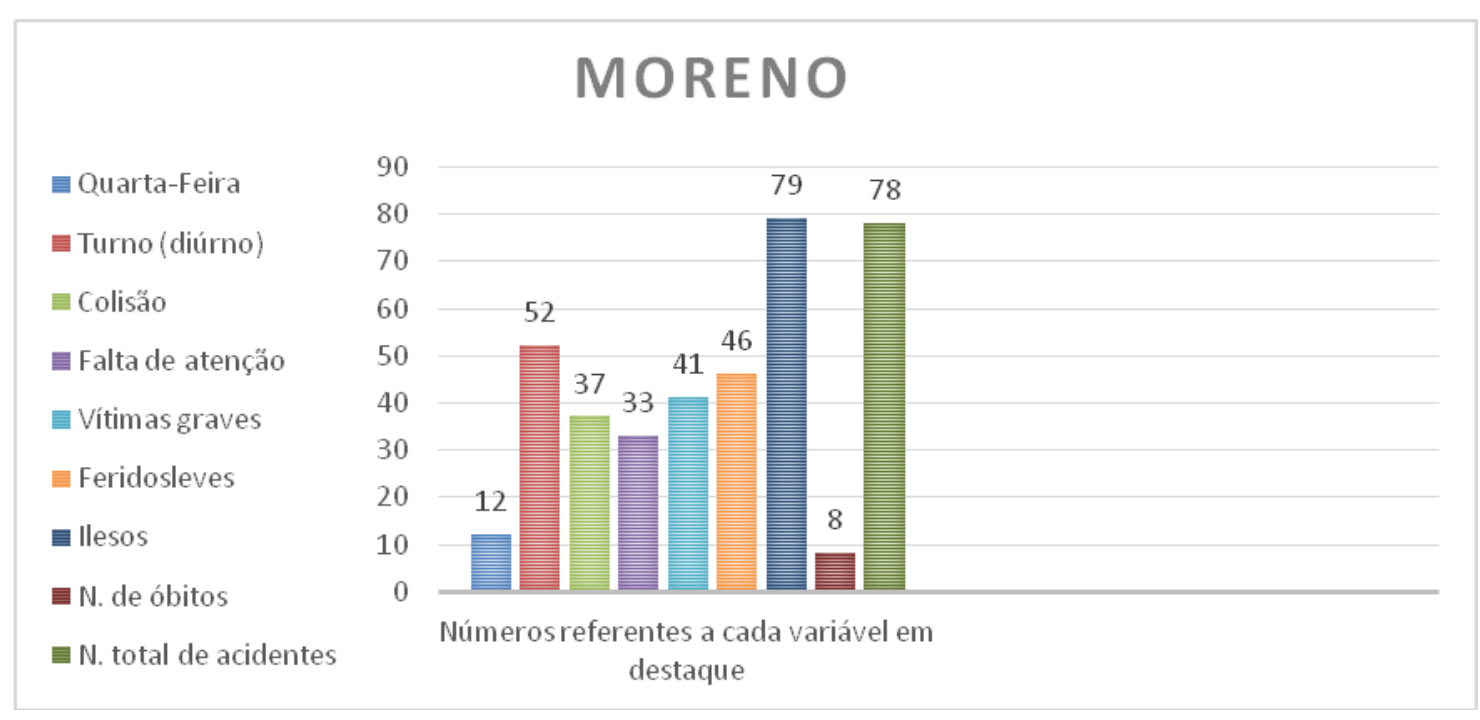

Fonte- Polícia Rodoviária Federal (PRF). 
Revista Científica do Corpo de Bombeiros Militar de Pernambuco

Artigo Publicado no Vol.06 N.16 - Edição Especial 2020 - ISSN 2359-4829

Versão on-line disponível em: http://www.revistaflammae.com

Figura 6.6 - Perfil dos acidentes por município (autor).

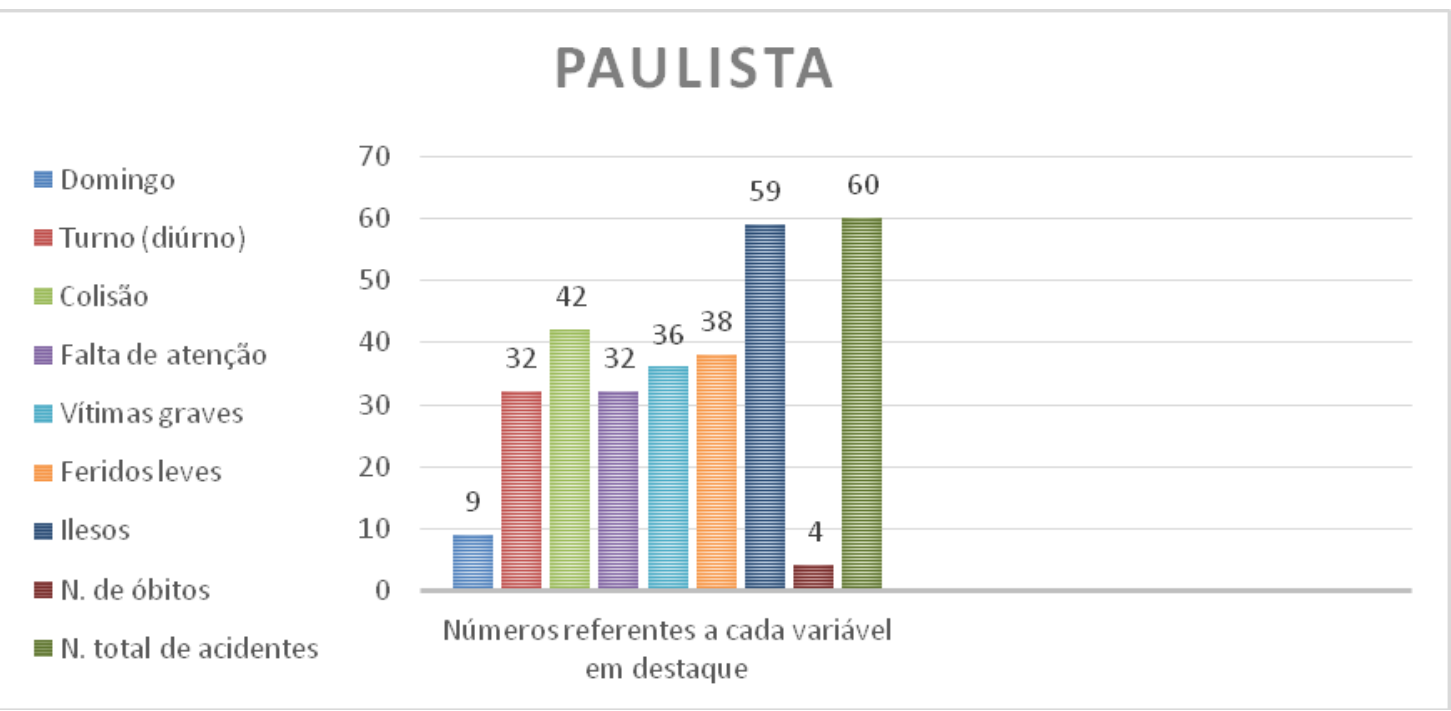

Fonte- Polícia Rodoviária Federal (PRF).

Figura 6.7 - Perfil dos acidentes por município (autor).

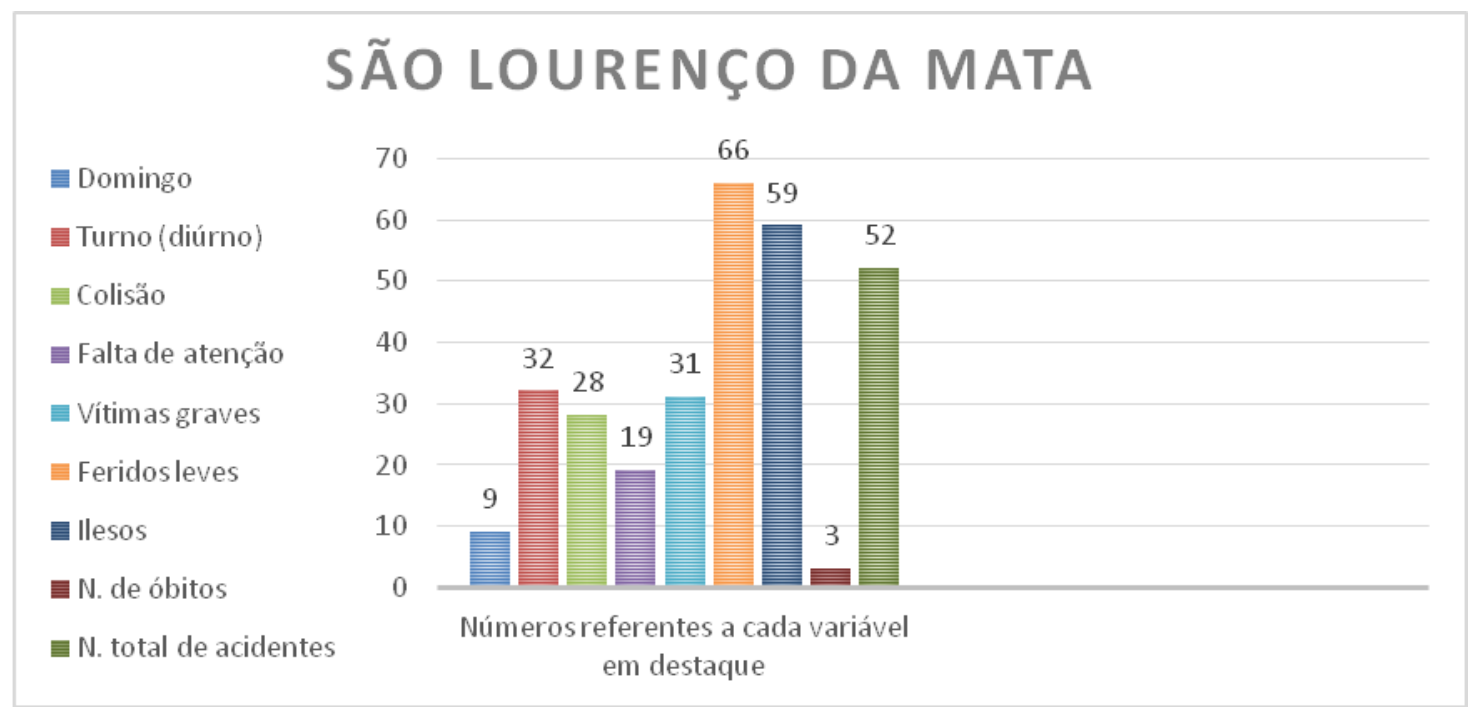

Fonte- Polícia Rodoviária Federal (PRF).

Figura 6.8 - Perfil dos acidentes por município (autor). 
Revista Científica do Corpo de Bombeiros Militar de Pernambuco

Artigo Publicado no Vol.06 N.16 - Edição Especial 2020 - ISSN 2359-4829

Versão on-line disponível em: $\underline{\text { http://www.revistaflammae.com }}$

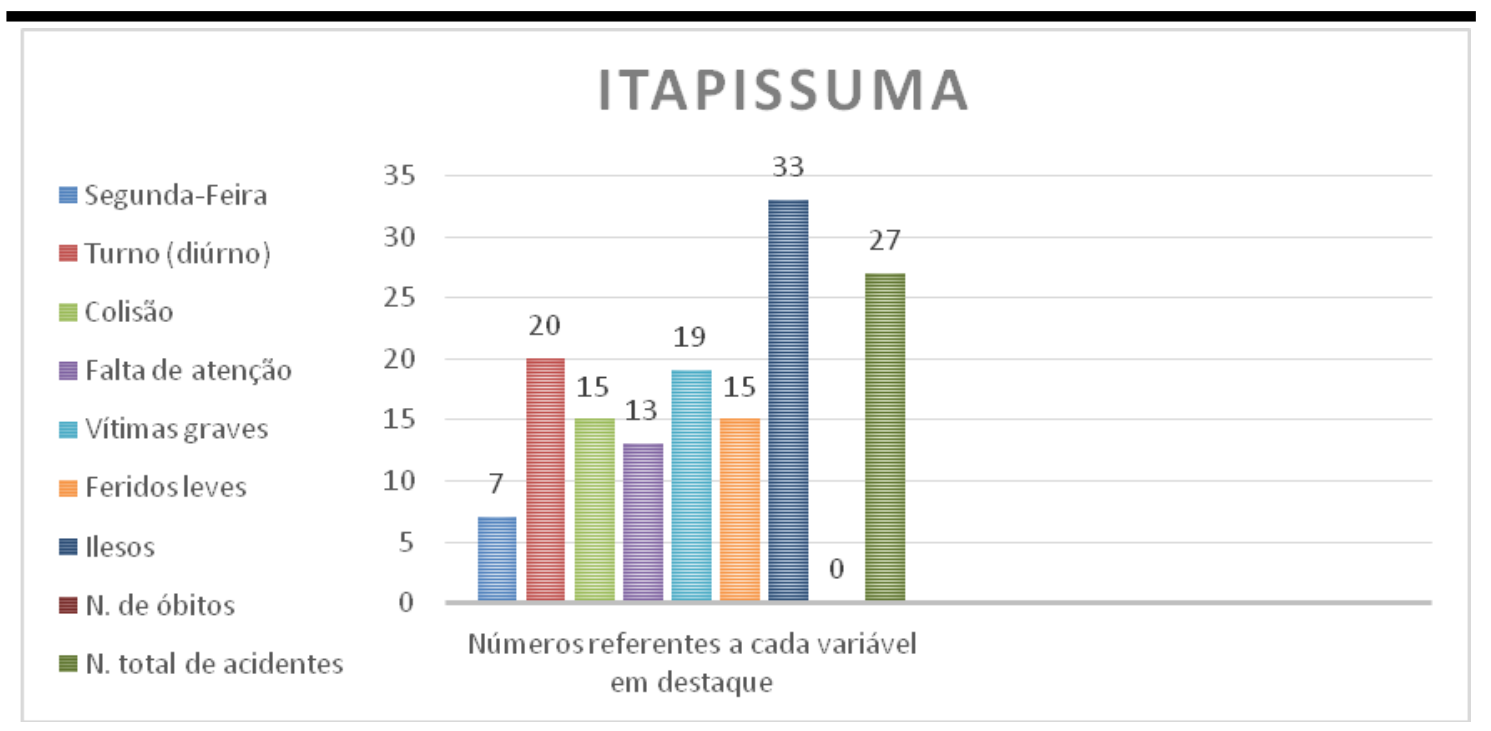

Fonte- Polícia Rodoviária Federal (PRF).

Figura 6.9 - Perfil dos acidentes por município (autor).

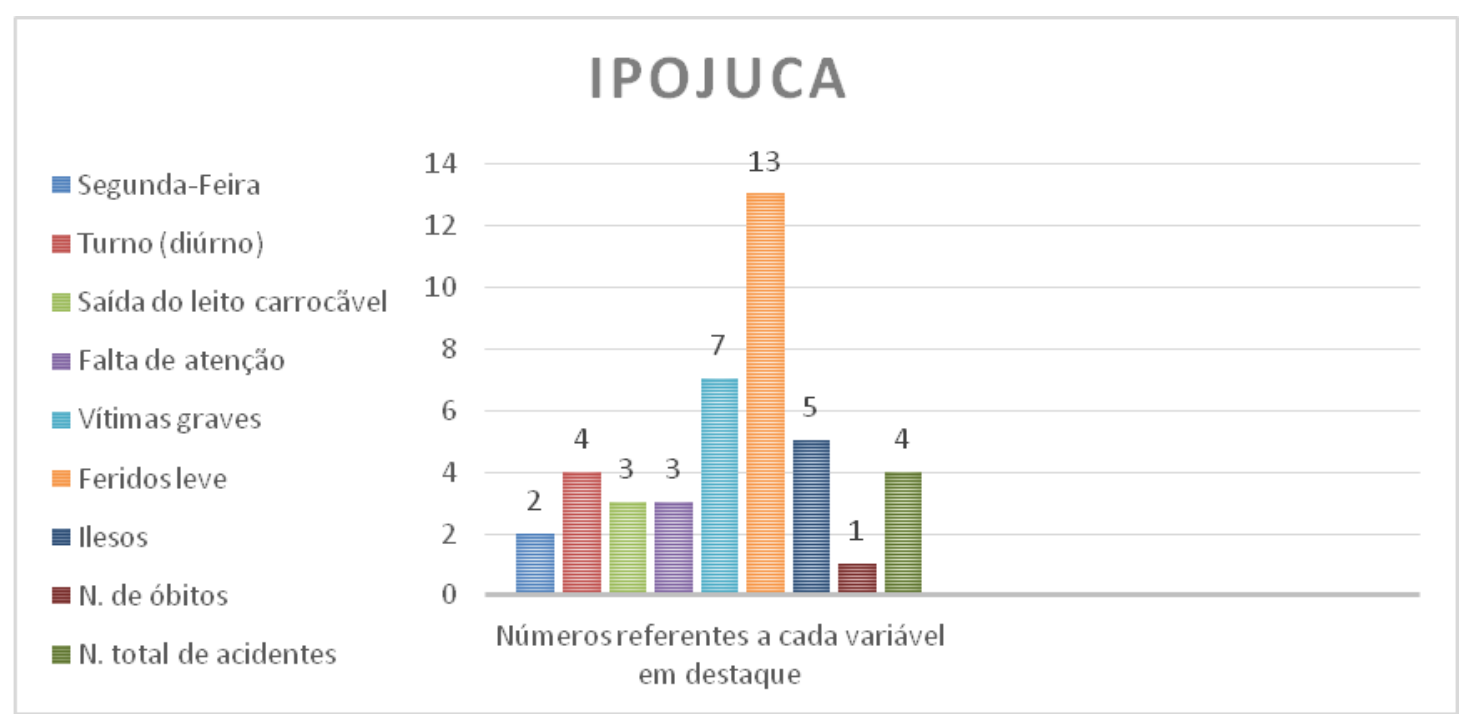

Fonte- Polícia Rodoviária Federal (PRF). 


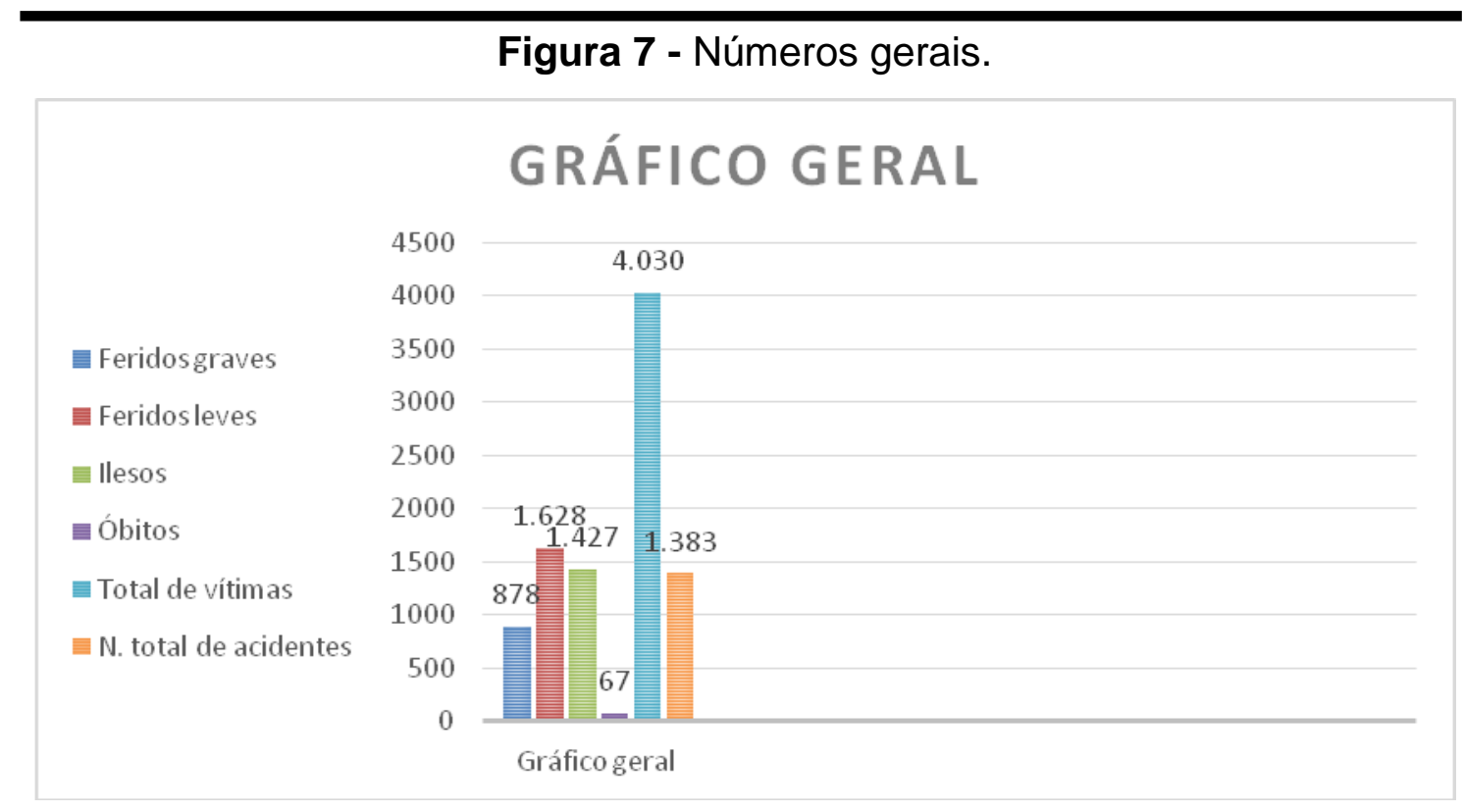

Fonte- Polícia Rodoviária Federal (PRF).

Os dados apontaram que alguns dos municípios que possuem as economias mais elevadas (IBGE, 2017) apresentam altos índices de acidentes, como mostra os resultados do estudo. Dessa forma, é possível supor que pode haver uma relação entre o número elevado de casos e os conglomerados comerciais, uma vez que ocorre o aumento do fluxo de veículo nessas localidades. Segundo Lima (2017), o Nordeste apresenta os maiores índices de ATT, afirmando que a elevação na liberação de crédito gerando mais densidade de veículos de todos os tipos nas, falta de manutenção e fiscalização nas estradas contribui diretamente para os altos índices de incidentes, chegando a citar os estados de Sergipe (SE) com $43,3 \%$ e Piauí (PI) com $34,7 \%$ em rankings nacionais.

Recife apresentou dados preocupantes, pois mesmo se tratando de apenas um município do estado de Pernambuco, mostrou percentuais consideráveis em relação ao número de ATT, chegando a 34,9\% dentro da sua área de abrangência. Os números apresentados por este município, podem ser comparados de maneira indireta, apenas para fins de observação, com os estados anteriormente citados por Lima, considerados como uns dos mais 
emergentes no cenário dos ATT, no Brasil. Dessa forma, podemos observar que a capital pernambucana apresenta índices semelhantes a grandes estados que são referências em ATT, situação que gera preocupação.

Os municípios de Recife, Igarassu, Abreu e Lima e Itapissuma apresentaram um perfil de colisões por falta de atenção nas SEGUNDASFEIRAS durante o dia, Jaboatão doa Guararapes e Cabo de Santo Agostinho apresentaram um perfil de colisões por falta de atenção nos SÁBADOS durante o dia, Paulista e São Lourenço da Mata demonstraram um perfil de colisões por falta de atenção nos domingos durante o dia, Moreno teve um perfil de colisões por falta de atenção nas QUARTAS-FEIRAS durante o dia e Ipojuca apresentou um perfil de saída do leito carroçável por falta de atenção nas SEGUNDAS-FEIRAS durante o dia. Os resultados indicaram que dentro da RMR existiu variação nos perfis dos acidentes $s$ de acordo com as ocorrências em cada município.

\section{CONSIDERAÇÕES FINAIS}

A variável dia da semana mais proeminente foi a SEGUNDA-FEIRA $(16,99 \%)$ dos acidentes, o turno foi o dia(65,58\%), o tipo de acidente com maior notificação foi a colisão( $61,82 \%)$,a causa principal foi a falta de atenção do condutor(49,45\%), em se tratando da classificação das vítimas, $63,41 \%$ apresentaram ferimentos graves e óbito foi 4,8\%. Após concluirmos a análise das variáveis e observarmos os resultados, encontramos o seguinte perfil: colisões por falda de atenção nas SEGUNDAS-FEIRAS durante o dia em 40\% dos municípios que foram analisados.

Dentre eles, podemos observar que Recife, a capital do estado, ficou no topo da lista com $34,9 \%$ dos incidentes, seguido por Jaboatão dos Guararapes $15,76 \%$ e Cabo de Santo Agostinho 12,87\%. Se observarmos os resultados através da ótica per capita, veremos que os três primeiros colocados nesta pesquisa, também fazem parte dos cinco com maior estrutura financeira do estado de Pernambuco (Recife, Jaboatão dos Guararapes, Ipojuca, Cabo de 
Santo Agostinho, Goiana), segundo censo do Instituto Brasileiro de Geografia e Estatística - IBGE, no ano de 2017.

Os resultados deste estudo, mostraram-se relevantes e confiáveis, uma vez que os dados foram extraídos de uma fonte confiável e ao comparar esta pesquisa com a de outros autores com publicações semelhantes, tivemos achados compatíveis.

Diante dos resultados apresentados, não podemos deixar de entrar na esfera financeira, pois o ATT, mobiliza toda sociedade para atenuar os danos que acometem a população e principalmente os que ameaçam a vida humana. Em 2001, esse agravo rendeu 453 milhões aos contribuintes e 5,3 bilhões em 2016, esse último, quase doze vezes o valor gasto em 2001, é referente apenas aos ATT envolvendo motocicletas (ANDRADE, 2015).

Segundo o Ipea (2015), os 170 mil ATT nas rodovias federais no ano de 2014, provocaram um custo altíssimo de 12,3 bilhões de reais para a sociedade. Grande parte desse valor (43\%) é relativo à perda da produtividade que as vítimas deixam de gerar durante seus afastamentos das atividades econômicas, bem como no caso de morte, provocando impacto direto na previdência social. O valor médio de cada acidente sem vítima fatal foi de $72.705,31$, já os que envolveram óbito tiveram custo de $646.762,94$. Em comparação entre 2007 e 2014, houve um aumento de 35\% dos gastos com ATT. Dessa forma, em 2014 os gastos gerais com ATT, estimou-se em 24,8 30,5 bilhões em média.

Por tanto, usar artifícios para diminuir essa estatística, além de reduzir os acidentes e mortes evitáveis, diminuirá, também, os custos que são empregados a toda população, que acaba pagando a conta, muito alta por sinal. Tal informação nos leva a refletir a respeito de como estão as aplicações de recursos na prevenção de ATT nos respectivos municípios, para a segurança da população em geral. É de natureza vital que as autoridades responsáveis atentem para a situação do trânsito, não apenas na RMR, mas em todo país e no mundo. 
Hoje, o Brasil tem um custo de bilhões em decorrência dos ATT, considerados, na maioria das vezes eventos evitáveis. Para tal, é necessário redirecionar mais recursos para estimular a prevenção e diminuição desse agravo através da intensificação de campanhas de conscientização, fazendo com que as informações cheguem a toda população, seja por mídia televisiva, nos sinais, nas escolas, nos estabelecimentos comerciais, principalmente dos que vendem bebidas alcoólicas e principalmente nas rádios, pois por mais simples que seja, todo lar possui acesso a esse meio de comunicação, fazendo a notícia alcançar o maior número de pessoas possíveis.

Por isso, acreditamos ser importe a confecção de estudos voltadas para a prevenção de agravos que acometem a coletividade e, espero que os resultados dessa pesquisa possam ser aplicados da melhor forma possível para contribuir na melhoria das condições no transito, prevenção de acidentes, conscientização, educação e não menos importante, na redução dos gastos públicos, além de ser uma contribuição para a meta da década 2011-2020 proposto pela ONU para todos os países, com o objetivo de reduzir as morbimortalidades decorrente do ATT.

Embora tenha apresentado resultados relevantes, esta pesquisa por si só ainda não pode determinar um conceito definido para a temática, pois carece de mais detalhes e aprofundamento sobre o tema, coisa que só poderá ocorrer em um futuro próximo, que será aplicado mais tempo para que haja avanço e, consequentemente, melhores resultados. Também, deve-se levar em consideração a escassez de conteúdos publicados para gerar uma boa discussão desse assunto.

Para esse enunciado, existe um leque gigantesco de possibilidades, pois a quantidade de dados disponíveis é extraordinária, não apenas pela fonte desse trabalho (PRF), mas por todos os órgãos fiscalizadores que semestralmente tornam públicos os seus balanços com um universo de dados que são capazes de nos fornece informações para traçar um perfil de acidentes 
não apenas de uma região metropolitana, mas de todo o estado ou do país. Existe uma grande chance dessa pesquisa tomar novas proporções.

Este artigo foi formulado para atender aos requisitos da graduação e posteriormente adaptado e submetido para publicação. Não consigo definir este feito de outro modo se não como bastante gratificante, principalmente agora que está finalizado. Foi um adversário poderoso, mas com a persistência e ajuda dos amigos e orientadores a batalha foi vencida. Espero, muito em breve, iniciar uma nota luta, agora com um pouco de experiência, tenho certeza de que será menos difícil de vencer esse próximo gigante.

\section{REFERÊNCIAS}

ANDRADE, S. S. C. de A. Panorama dos acidentes de transporte terrestre no Brasil: das internações às sequelase ao óbito: uma contribuição para a suavigilância. 2015. Tese de Doutorado. Universidade de São Paulo.

BARROS, C.DE S. et al. Caracterização dos acidentes de transporte terrestre ocorridos em rodovias federais. Arq. Ciênc. Saúde. 2018 jan-mar: 25(1) 35-4

BERTHO, A. C. S. et al. Mortes por acidentes de trânsito nas capitais do nordeste e do sudeste: diferenças regionais. Anais, p. 1-19, 2017.

MEDEIROS, W. M. DA C. et al. Perfil epidemiológico das vítimas de acidentes de trânsito atendidas num serviço público de emergência da região metropolitana de Natal/RN. HOLOS, v. 7, p. 213-224, 2017.

SANTOS, M. A. DA S.;SANTOS, L. G. E. DOS.;OLIVEIRA, G. F. S. DE M.;\&IRANDA, L. N. (2018). Assistência de enfermagem ao paciente politraumatizado. Caderno de Graduação-Ciências Biológicas e da SaúdeUNIT-ALAGOAS, 4(3), 11.

DIAS, L. K. S. et al. Caracterização dos acidentes de trânsito atendidos pelo serviço de atendimento móvel de urgência. SANARE-Revista de Políticas Públicas, v. 16, 2017. 
ESTATístICA, I. B. D. G. E. IBGE. Produto Interno Bruto dos Municípios, 2017.

<https://cidades.ibge.gov.br/brasil/pe/recife/pesquisa/38/47001?tipo=ranking>. Acesso em: 15 junho 2020.

FEDERAL, P. R. Dados dos acidentes nas rodovias federais. Brasil: [s.n.], 2017

IPEA, I. D. P. E. A. Ipea - Instituto de Pesquisa Econômica Aplicada. ACIDENTES DE TRÂNSITO NAS RODOVIAS FEDERAIS BRASILEIRAS CARACTERIZAÇÃO, TENDÊNCIAS E CUSTOS PARA A SOCIEDADE, 2015. Disponivel em: <file:///C:/Users/rober/Downloads/ARTIGOS/lpea.pdf>. Acesso em: 16 junho 2020.

LEOPOLDO, K.; LEYTON, V.; OLIVEIRA, L. G. DE. Uso exclusivo de álcool e em associação a outras drogas entre motoristas de caminhão que trafegam por rodovias do Estado de São Paulo, Brasil: um estudo transversal. Cadernos de Saúde Pública, v. 31, p. 1916-1928, 2015.

LIMA, R. R. Morbidade e mortalidade devido a acidentes de transporte nas Rodovias Federais da Grande Aracaju nos anos de 2007 a 2016. 2017.

MARCELO, I. S. Estudo da mortalidade por acidentes de trânsito em Aracaju (SE), 2013, Aracajú, Outubro 2017. 34-40. Disponivel em: <file:///C:/Users/rober/Downloads/ARTIGOS/Marcelo.pdf>. Acesso em: 16 junho 2020.

SCHMIDT, R. G. Implementação de base de dados em ferramentas de data mining: estudo da segurança viária em rodovias federais brasileiras. 2018. 